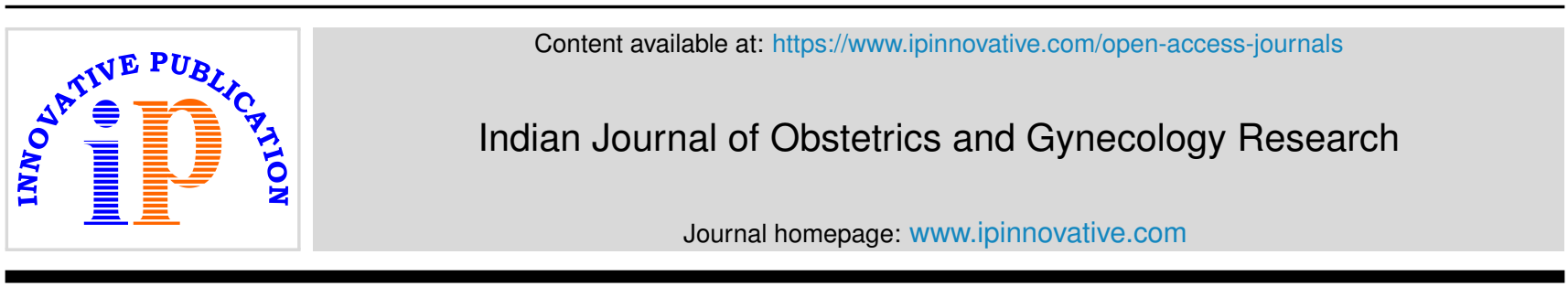

Original Research Article

\title{
Knowledge awareness and practices of married women towards emergency contraceptives methods
}

\author{
Uday Mohanlal Patel ${ }^{1, *}$ \\ ${ }^{1}$ Dept of Obstetrics \& Gynaecology, GMERS Medical College, Patan, Gujarat, India
}

\section{A R T I C L E I N F O}

\section{Article history:}

Received 30-06-2020

Accepted 25-07-2020

Available online 12-09-2020

\section{Keywords:}

Awareness

Emergency contraceptives (EC)

Methods

Women

\begin{abstract}
A B S T R A C T
Background and Aim: Emergency contraception (EC) is usage of contraceptive method after an unprotected sexual intercourse. It provides a window of opportunity for females for prevention of an unplanned pregnancy. In India, emergency contraceptive usage continues to be very poor. Thus, this study was planned to analyse the knowledge, awareness, and practices of married women in Haryana towards EC methods.

Materials and Methods: This observational study was undertaken in a single centre on a section of rural and urban population in Haryana. A total of 500 women of reproductive age group were included in the study. A series of questions were asked in a face to face interview from a pre-structured questionnaire in a non-formal yet confidential environment. The data were collected, analysed, and compared with data available in literature.

Results: In our study, more than $80 \%$ women have heard of EC. Of those who were aware, majority knew about EC pills. IUD as EC was known to a very few women. Television was the most common source of information followed by family and friends. Very few women knew the correct time for taking the EC pills. Conclusion: Our study affirms a poor knowledge about use of emergency contraception among women in Haryana. Imparting knowledge through television, social media and incorporating and highlighting EC use in sex education programs can greatly help to increase the awareness and knowledge of correct EC use.

(C) 2020 Published by Innovative Publication. This is an open access article under the CC BY-NC license (https://creativecommons.org/licenses/by-nc/4.0/)
\end{abstract}

\section{Introduction}

Emergency contraception is defined as the use of drugs or devices to prevent pregnancy within a few days of unprotected coitus. It is sometimes referred to as 'morning after' or post coital contraception. India is the second most populous country in the world, with over 1.30 billion people, more than a sixth of the world's population. ${ }^{1}$ Already containing $17.5 \%$ of the world's population India more people to its population every year than any other country, and in fact the individual population of some of its states is equal to the total population of many countries. For example, Population of Uttar Pradesh (state in India) almost equals to the population of Brazil. 2,3

\footnotetext{
* Corresponding author.

E-mail address: udaypate11810@gmail.com (U. M. Patel).
}

Emergency contraception is essentially female driven, so its use and success rests mainly on how women perceive and practice it. It offers women a last chance to prevent pregnancy after unprotected intercourse. Women deserve that last chance and barriers to the availability of emergency contraception should be eliminated. The ability of women to control their own fertility is absolutely fundamental to women's empowerment and equality. ${ }^{4}$

Emergency Contraception (EC) is a safe and extremely effective method which was introduced three decades ago as a means to reduce the rates of unintended pregnancies, induced abortions, and unwanted childbirth. In spite of being introduced in the National Family Welfare Programme in 2003 and later declared as an Over-the-counter drugs, (OTC) product in 2005 it still remains a grossly underutilized option in the prevention of pregnancy. 5 
In developing countries, the World Health Organization (WHO) estimates that one woman dies every eight minutes due to unsafe abortions. Annually, around five million women who undergo unsafe abortions require hospitalization. ${ }^{6}$ In these nations, ECP is the most commonly used method of EC after unprotected sexual intercourse to prevent unwanted and unintended pregnancy. ${ }^{7}$ But still about one in six married women faces an unmet need for contraceptive. A detailed data from 8 states covered in the Annual Health Survey showed a very low (less than 0.2 percent) use of ECP. With this background, a study was thus planned with an aim to identify the knowledge, awareness and practise of emergency contraception in a population of Gujarat.

\section{Materials and Methods}

The present study was done in the single centre of the urban and rural in the Gujarat population over the period of 6 months. A total of 250 women of the age group of $15-46$ years were included in the study. The women who were over or under age other than the age range were excluded from the study. The women who were unwilling to participate also were excluded from study.

The preformed questionnaire was prepared by the two qualified personal. All the study included participants were asked a series of question from the preformed questionnaire. All the questions were asked in the local language. All the workers were trained to ask the question in the normal yet confidential manner. The informed consent was taken from all the participants. The ethical committee of the institution was informed about the study and the ethical clearance certificate was obtained from it.

The questionnaire did consist of two parts. The first part of questionnaire consists of detail demographic history and the second part consists of awareness related to emergency contraceptives. Knowledge, administration, side effects and availability information were assessed. Various perceptions like fear and myths were also noted as the best of the knowledge.

Knowledge regarding EC effect on sexual behaviour and fertility in general was also evaluated. After the questionnaire, opportunistic counselling was done and people were encouraged to ask queries and encouraged to get further awareness from the investigating team. Information on benefits of EC methods, correct usage, timing, clearing doubts regarding EC methods, and queries regarding regular contraception were also discussed.

\subsection{Statistical analysis}

The recorded data was compiled and entered in a spreadsheet computer program (Microsoft Excel 2007) and then exported to data editor page of SPSS version 15 (SPSS Inc., Chicago, Illinois, USA). For analysis, the variables were summarized using descriptive summary measures, expressed as mean for continuous variables, and percentage for categorical variables.

\section{Results}

A total of 250 were included in the study. The socioeconomic data of the women who participated in the study were recorded with detail history and summarize in the Table 1 . Of the total 250 women, the literacy rate was found in 210 women were as rest of the 40 women were found to be illiterate. Owing to the background 130 women were found to be from rural area and rest 120 women were from urban area. When the question related to occupation was asked, majority of the women were house wife. Regarding their family background majority of them use to live in joint family. When questions pertaining to knowledge and usage of EC were asked, majority of them were aware of usage of emergency contraceptives. Those who were aware or had the knowledge related to the EC, only those women were further questioned for the depth of knowledge and awareness related to emergency contraceptives.

Table 1: Demographic data of the women participants

\begin{tabular}{lc}
\hline Variables / characteristics & No. of women \\
Age & \\
$15-24$ & 110 \\
$25-34$ & 80 \\
$35-36$ & 70 \\
Place of residence & \\
Rural & 130 \\
Urban & 120 \\
Socioeconomic status & \\
Higher & 30 \\
Middle & 124 \\
Lower & 96 \\
Education level & \\
Literate & 210 \\
Illiterate & 40 \\
Occupation of women & \\
House wife & 174 \\
Service & 22 \\
Labour & 54 \\
Type of family & \\
Nuclear & 33 \\
Joint & 217 \\
\hline & \\
\hline & \\
&
\end{tabular}

Second part of questioner was related to the emergency contraceptives. Majority of the women knew only about the contraceptive pills as the method, very few were aware about the IUD methods. Of those who were aware of the contraceptives pills, many of them have used it. When the question related to the source of knowledge and information was asked television was found to be the main source of information followed by friends and husbands and social 
media. In context to the questions related to the time of consumption of EC pills, majority of them had no idea about the ideal time for the taking EC pills. Some of the women had misconception related to the use of herbs and spices taken after unprotected sex can prevent their pregnancy. Participants were encouraged to disseminate the information of EC given to them to other women and majority of them agreed to do so.

Table 2: Women's awareness in relation to emergency contraceptives

\begin{tabular}{lc}
\hline $\begin{array}{l}\text { Characteristic variables for EC } \\
\text { knowledge } \\
\text { Ever heard about the emergency } \\
\text { contraceptives? }\end{array}$ & No. of women \\
Yes & 200 \\
No & 50 \\
Have ever used EC pills? & \\
Yes & 144 \\
No & 46 \\
Awareness of EC methods available? & \\
IUD & 20 \\
Pills & 172 \\
Others & 8 \\
Source of information related to EC & \\
Television & 193 \\
Friends & 116 \\
Husband & 92 \\
Social media & 55 \\
Proper time to take EC pills awareness? & \\
Before UPSI & 10 \\
Within 72 hours & 16 \\
More than 72 hours & 6 \\
Don't know & 168 \\
\hline
\end{tabular}

\section{Discussion}

Unintended pregnancies contribute to the rapid population growth that impairs desperately needed social and economic progress. If family planning programs are not strengthened and nor successful, and if current fertility where to remain unchanged, world population would increase in size. ${ }^{8}$

Although India was the first country in the world to introduce a National Family planning programme as early as during the first five-year plan (1951-1956) to control population explosion. The unmet need for family planning among currently married women is still 13 percent in India. Although in India it is estimated that CPR is $56 \%$ only $10 \%$ are using spacing methods. Numerous contraceptive techniques both temporary and permanent have been introduced by family welfare department of India. ${ }^{9,10}$

The present study was conducted in the section of urban and rural Rajasthan population. Majority of the women were aware of the emergency contraceptives in the current study.
About the 200 women have heard about the emergency contraceptives. In a study by Myer et al, overall awareness was found to be $30 \%$ in a cohort of women in South Africa.

Prevention of these unplanned pregnancies will go a long way in improving the reproductive health of women in India as failure rate of Emergency Contraception is varying from $0-2.4 \%$ depending on the method used interval between coitus and method use and relationship of coitus to ovulation. But all methods are ineffective once implantation has already occurred. ${ }^{9,11}$

The present study states that around $80 \%$ women have heard and had some or the other knowledge related to the emergency contraceptives. The reason of this that main source of information was found to be television and friends and social media. Friends and family members were also found to be source of information but that source was found to be unreliable and the amount of information obtained is also less. In the present study the family source and the friends' percentage as the source was found to be very less.

Awareness of EC is poor even among the general practitioners and specialist doctors and young interns are aware of EC, but they lack an accurate and detailed knowledge regarding its composition, dosage schedule and efficacy. Patients rarely seek help in cases of condom failure and unprotected intercourse.

\section{Conclusion}

Based on the findings, it is concluded that on an average majority of women have adequate knowledge on emergency contraception as a whole. Majority of them are likely to have mix attitude towards EC. There is a need for aggressive advocacy about female reproductive health and dissemination of information on family planning methods among the reproductive females. However the improvement of womens' knowledge about specific details of the method and timely utilization of emergency contraception is still required.

\section{Source of Funding}

None.

\section{Conflict of Interest}

None.

\section{References}

1. Meyer JL. Emergency contraception and Ball State University students: an honors thesis (HONRS 499); 2007.

2. Ortman JM, Velkoff VA, Hogan H. An aging nation: the older population in the United States: United States Census Bureau, Economics and Statistics Administration, US ...; 2014.

3. Gwatkin DR, Rutstein S, Johnson K, Suliman E, Wagstaff A, Amouzou A. Socio-economic differences in health, nutrition, and population within developing countries: an overview. Niger J Clin Pract. 2007;10(4):272-82. 
4. Saini S, Kamra D, Singh S. Knowledge, attitude and practices regarding emergency contraception among married women in Ludhiana, Punjab, India. Int J Community Med Public Health. 2018;5(8):3506.

5. Nivedita K, Shanthini F. Knowledge, attitude and practice of emergency contraception on nursing personnel. Journal of clinical and diagnostic research. J Clin Diagn Res. 2014;8(9):20-2.

6. Grimes DA, Benson J, Singh S, Romero M, Ganatra B, Okonofua FE, et al. Unsafe abortion: the preventable pandemic. Lancet. 2006;368:1908-19.

7. Trussell J, Raymond EG, K C. Emergency contraception: A last chance to prevent unintended pregnancy. Contemp Readings Law Soc Justice. 2014;p. 6.

8. Speidel JJ, Weiss DC, Ethelston SA, Gilbert SM. Population policies, programmes and the environment. Philos Trans $R$ Soc. 2009;364:3049-65.

9. Singh V, Thakur P, Nayak P, Agrawal S. Knowledge attitude and practice (KAP) of emergency contraceptive pills among women of reproductive age group attending AIIMS OPD Raipur (C.G.). Int $J$ Adv Med. 2014;1(2):105-12.

10. Prusty RK. Use of contraceptives and unmet need for family planning among tribal women in India and selected hilly states. J Health. 2014;32:342.

11. Manjula R. An Educational Intervention Study on Safe Sex Among Preuniversity Girls in Davangere city; 2009.

\section{Author biography}

Uday Mohanlal Patel Associate Professor

Cite this article: Patel UM. Knowledge awareness and practices of married women towards emergency contraceptives methods. Indian J Obstet Gynecol Res 2020;7(3):352-355. 